\title{
Long memory and multifractality: A joint test
}

John Goddard

Bangor Business School, Bangor University - Hen Goleg, College Road, Bangor, LL57 2DG, United Kingdom

\section{Enrico Onali*}

Aston Business School, Aston University - Aston Triangle, Birmingham, B4 7ET, United Kingdom

*Corresponding author

\begin{abstract}
The properties of statistical tests for hypotheses concerning the parameters of the multifractal model of asset returns (MMAR) are investigated, using Monte Carlo techniques. We show that, in the presence of multifractality, conventional tests of long memory tend to overreject the null hypothesis of no long memory. Our test addresses this issue by jointly estimating long memory and multifractality. The estimation and test procedures are applied to exchange rate data for 12 currencies. Among the nested model specifications that are investigated, in 11 out of 12 cases, daily returns are most appropriately characterized by a variant of the MMAR that applies a multifractal time-deformation process to NIID returns. There is no evidence of long memory.
\end{abstract}

Keywords: Multifractality, long memory, volatility clustering, exchange rate returns 


\section{Long memory and multifractality: A joint test}

\section{Introduction}

The statistical properties of financial asset returns are of key importance for finance theory, and for portfolio and risk management. The econophysics literature has grown rapidly in volume over the past two decades, and fractal models have been employed to explain empirical regularities at odds with mainstream financial economics theory, such as: powerlaws and self-similarity [1], long memory in returns and volatility [2-4], and multifractality [5]. Multifractality in financial returns data has been interpreted as evidence of financial market inefficiency [6], or herding behaviour in financial markets [7].

The multifractal model of asset returns (MMAR) is capable of accommodating exceptional events (large shocks), and can represent either normal or non-normal log returns with a finite variance [8]. The MMAR nests the fractionally-integrated $\operatorname{ARFIMA}(0, \mathrm{~d}, 0)$ model, which allows for long memory in returns, and can also accommodate long memory in volatility associated with multifractality in the trading process. Long memory in returns does not necessarily imply multifractality, and vice versa. Thus, the MMAR is able to replicate the pricing behaviour of many types of financial assets.

The MMAR describes a continuous-time process, constructed by compounding fractional brownian motion (FBM) with a random, multifractal time-deformation process. The time-deformation process allows for volatility clustering in log returns measured at any time scale, and for long memory in volatility.

The property of multifractality is identified empirically through estimation of the moment scaling function, $\mathrm{E}\left(\left|\Delta^{(\mathrm{n})} \mathrm{p}_{\mathrm{t}}\right|^{\mathrm{q}}\right)$, where $\mathrm{p}_{\mathrm{t}}$ is $\log$ price, and $\Delta^{(\mathrm{n})} \mathrm{p}_{\mathrm{t}}=\mathrm{p}_{\mathrm{t}}-\mathrm{p}_{\mathrm{t}-\mathrm{n}}$ is the $\log$ return measured over the time scale n, over a range of values for q. Multi-scaling behaviour implies different exponents characterize the variation of different q-moments of the unconditional distribution of returns as the time scale $\mathrm{n}$ changes. The scaling function 
captures the intuition that different economic factors, such as technological shocks, business cycles and liquidity shocks, have different time scales, and that the volatility arising from shocks associated with different factors may have different degrees of persistence [8], [9]. The MMAR allows for a wide range of behaviour in the tails of the unconditional distribution of returns, including fat tails at high frequencies [10]. Consistent with many financial returns series, including exchange rate returns, the MMAR allows the tails of the unconditional distribution to become thinner as the time scale increases; but the distribution need not converge to a normal distribution at the lowest frequencies [9].

Previous empirical studies employ methods such as Multi-Fractal Detrended Fluctuation Analysis [5, 11, 12, 13, 14], Wavelet Transform Modulus Maxima [11] or a Generalized Hurst Exponent approach [15] to detect multifractality. In this study, we develop statistical testing criteria for jointly-estimated long memory and multifractality parameters, based on a conventional hypothesis-testing methodology. In so doing, we facilitate comparisons between processes that are described by the MMAR, and processes that are characterized by model specifications nested within the MMAR. The latter include NIID (normal, independent and identically distributed) returns, and long-range dependent returns generated from a log price series characterized by FBM. Monte Carlo simulations are used to generate critical values for the relevant tests.

The methods are illustrated by fitting the MMAR to the daily log returns series for the exchange rates of 12 currencies against the US dollar for the period 1993-2012. Prior literature indicates that key empirical features of exchange rate returns data, including long memory in volatility, multi-scaling behaviour, and fat tails, can be represented parsimoniously using a multifractal framework [8], [16], [17], [18], [19]. Our results suggest that the data can be characterized by a variant of the MMAR that is constructed by compounding NIID returns with a multifractal time-deformation process; but the more 
general formulation, in which FBM is compounded with a multifractal time-deformation process, is not supported. ${ }^{1}$

This paper proceeds as follows. The next section describes the MMAR. Section 3 provides an explanation of how the main parameters of the MMAR can be estimated. Section 4 introduces a joint hypothesis testing framework for long memory and multifractality and Section 5 reports the results of tests based on this method as applied to foreign exchange rates data. Section 6 concludes the paper.

\section{The multifractal model of asset returns}

According to the MMAR, $\mathrm{p}_{\mathrm{t}}=\mathrm{B}_{\mathrm{H}}[\theta(\mathrm{t})]$, where $\mathrm{B}_{\mathrm{H}}[]$ denotes FBM, and $\theta(\mathrm{t})$ denotes a time-deformation process. In order to construct $\theta(t)$, consider first the case $T=2^{K}$ for some integer value of $K$. The specification of $\theta(t)$ is

$\Delta \theta(\mathrm{t})=\theta(\mathrm{t})-\theta(\mathrm{t}-1)=\mathrm{T} \Omega^{-1} \prod_{\mathrm{k}=1}^{\mathrm{K}} \mathrm{m}\left[\eta_{\mathrm{t}}(\mathrm{k})\right]$, where $\Omega=\sum_{\tau=1}^{\mathrm{T}} \prod_{\mathrm{k}=1}^{\mathrm{K}} \mathrm{m}\left[\eta_{\tau}(\mathrm{k})\right]$

where $\eta_{\mathrm{t}}(\mathrm{k})=\mathrm{h}$ if $2^{-\mathrm{k}}(\mathrm{h}-1) \mathrm{T}+1 \leq \mathrm{t} \leq 2^{-\mathrm{k}} \mathrm{hT}$ for $\mathrm{k}=1 \ldots \mathrm{K}, \mathrm{h}=1 \ldots \mathrm{k}$, and $\mathrm{t}=1 \ldots \mathrm{T}$; and the multiplier $\mathrm{m}\left[\eta_{\mathrm{t}}(\mathrm{k})\right]$ is assumed to be drawn randomly from a lognormal distribution with mean $\lambda$ and variance $\sigma^{2}=2(\lambda-1) / \ln 2$ for $\lambda>1$.

In the case $\mathrm{T} \neq 2^{\mathrm{K}}$ for any integer value of $\mathrm{K}$, the following adjustments are required. Let $\mathrm{K}^{*}$ denote the minimum value of $\mathrm{K}$ such that $\mathrm{T}<2^{\mathrm{K}}$. The multipliers $\mathrm{m}\left[\eta_{\mathrm{s}}(\mathrm{k})\right]$ are constructed in accordance with the procedure described above, for $\mathrm{k}=1 \ldots \mathrm{K}$ and $\mathrm{s}=1 \ldots 2^{\mathrm{K}^{*}}$.

$\Delta \theta(\mathrm{t})=\mathrm{T} \Omega^{-1} \prod_{\mathrm{k}=1}^{\mathrm{K}} \mathrm{m}\left[\eta_{\mathrm{r}+\mathrm{t}}(\mathrm{k})\right]$, where $\Omega=\sum_{\tau=\mathrm{r}+1}^{\mathrm{r}+\mathrm{T}} \prod_{\mathrm{k}=1}^{\mathrm{K}} \mathrm{m}\left[\eta_{\mathrm{r}+\tau}(\mathrm{k})\right]$

where $\mathrm{r}$ is a randomly drawn integer, distributed uniformly over the interval $\left(0, \mathrm{~K}^{*}-\mathrm{T}\right)$.

\footnotetext{
${ }^{1}$ A methodological approach that involves fitting a multifractal model to data, and drawing inferences from the fitted parameter values, has a longstanding tradition in the multifractality literature, extending back to [20]. In this study and elsewhere, multifractality is the (model-dependent) alternative hypothesis against which null hypotheses favouring a more parsimonious model specification are tested.
} 
Let $\mathrm{u}_{\mathrm{t}} \sim \mathrm{N}(0, \Delta \theta(\mathrm{t}))$. For $\lambda=1, \Delta \theta(\mathrm{t})=1$ for all $\mathrm{t}$. $\mathrm{u}_{\mathrm{t}}$ is homoscedastic and there is no multifractality in $u_{t}$. For $\lambda>1, u_{t}$ is heteroscedastic and there is multifractality in $u_{t}$. Combining the multifractal time-deformation process with FBM such that $p_{t}=B_{H}[\theta(t)]$, the data generating process for $\Delta^{(1)} \mathrm{p}_{\mathrm{t}}$ is

$(1-\mathrm{L})^{\mathrm{d}} \Delta^{(1)} \mathrm{p}_{\mathrm{t}}=\mathrm{u}_{\mathrm{t}}$

where $\mathrm{L}$ denotes the lag operator $\mathrm{L}^{\mathrm{s}} \Delta^{(1)} \mathrm{p}_{\mathrm{t}}=\Delta^{(1)} \mathrm{p}_{\mathrm{t}-\mathrm{s}}$ for $\mathrm{s}=0,1,2, \ldots$

Using the Wold decomposition, the moving average representation of FBM is

$\Delta^{(1)} \mathrm{p}_{\mathrm{t}}=(1-\mathrm{L})^{-\mathrm{d}} \mathrm{u}_{\mathrm{t}}=\left[1+\mathrm{dL}+\{\mathrm{d}(\mathrm{d}-1) / 2 !\} \mathrm{L}^{2}+\{\mathrm{d}(\mathrm{d}-1)(\mathrm{d}-2) / 3 !\} \mathrm{L}^{3}+\ldots\right] \mathrm{u}_{\mathrm{t}}$

$\Delta^{(1)} p_{t}$ is stationary for $-0.5<\mathrm{d}<0.5$. Let $\mathrm{H}=\mathrm{d}+0.5$ denote the Hurst exponent. The variance of log returns has the following scaling property

$\operatorname{var}\left[\Delta^{(\mathrm{n})} \mathrm{p}_{\mathrm{t}}\right]=\mathrm{n}^{2 \mathrm{H}} \operatorname{var}\left[\Delta^{(1)} \mathrm{p}_{\mathrm{t}}\right]$

Let $\gamma_{\mathrm{k}}=\mathrm{E}\left(\Delta^{(1)} \mathrm{p}_{\mathrm{t}} \Delta^{(1)} \mathrm{p}_{\mathrm{t}-\mathrm{k}}\right) / \mathrm{E}\left(\Delta^{(1)} \mathrm{p}_{\mathrm{t}}^{2}\right)$ for $\mathrm{k}=0,1,2, \ldots$ denote the autocovariance function of $\Delta^{(1)} \mathrm{p}_{\mathrm{t}}$. For $\mathrm{d}=0(\mathrm{H}=0.5), \mathrm{p}_{\mathrm{t}}$ is a martingale, and $\gamma_{\mathrm{k}}=0$ for $\mathrm{k} \geq 1$. For $-0.5<\mathrm{d}<0(0<\mathrm{H}<0.5), \Delta \mathrm{p}_{\mathrm{t}}$ exhibits negative persistence, and $\gamma_{\mathrm{k}}<0$ for $\mathrm{k} \geq 1$. For $0<\mathrm{d}<0.5(0.5<\mathrm{H}<1), \Delta \mathrm{p}_{\mathrm{t}}$ exhibits positive persistence and long memory, and $\gamma_{\mathrm{k}}>0$ for $\mathrm{k} \geq 1$.

\section{Estimation of the parameters of the MMAR}

Following the method described by [8], estimation of the two parameters of interest in the MMAR, $\{\mathrm{H}, \lambda\}$, proceeds as follows. Starting from the first observation, subdivide the sample period $\mathrm{T}$ into $\mathrm{M}$ contiguous subperiods, each containing $\mathrm{n}$ observations such that $\mathrm{T}-\mathrm{n}$ $<\mathrm{Mn} \leq \mathrm{T}$. Let $\mathrm{V}_{\mathrm{m}}$ denote the absolute value of the $\log$ return calculated over the $\mathrm{n}$ observations within subperiod $\mathrm{m}$, for $\mathrm{m}=1 \ldots \mathrm{M}, \mathrm{v}_{\mathrm{m}}=\left|\mathrm{p}_{\mathrm{mn}}-\mathrm{p}_{\mathrm{m}(\mathrm{n}-1)}\right|$.

If $\mathrm{Mn}<\mathrm{T}$, then $\mathrm{L}=\mathrm{T}-\mathrm{nM}$ observations at the end of the sample period are unused in the calculation of $\left\{\mathrm{v}_{\mathrm{m}}\right\}$. In order to incorporate these observations into the analysis, the above 
calculation is repeated, starting from the $L+1$ th observation. A second set of $M$ values of $\left\{\mathrm{v}_{\mathrm{m}}\right\}$ is obtained, labelled (for convenience) $\left\{\mathrm{v}_{\mathrm{m}+1} \ldots \mathrm{v}_{2 \mathrm{M}}\right\}$. If $\mathrm{Mn}=\mathrm{T},\left\{\mathrm{v}_{1} \ldots \mathrm{v}_{\mathrm{M}}\right\}$ and $\left\{\mathrm{v}_{\mathrm{M}+1} \ldots \mathrm{v}_{2 \mathrm{M}}\right\}$ are identical. The q'th-order partition function for scale $\mathrm{n}$ is

$\mathrm{S}_{\mathrm{q}}(\mathrm{T}, \mathrm{n})=2^{-1} \sum_{\mathrm{m}=1}^{2 \mathrm{M}}\left(\mathrm{v}_{\mathrm{m}}\right)^{\mathrm{q}}$

$\mathrm{S}_{\mathrm{q}}(\mathrm{T}, \mathrm{n})$ is calculated for various values of $\mathrm{q}$, and for each $\mathrm{q}$ for various values of $\mathrm{n}$. The scaling behaviour of $\mathrm{S}_{\mathrm{q}}(T, n)$ is investigated by examining the power law relationship $\mathrm{E}\left[\mathrm{S}_{\mathrm{q}}(\mathrm{T}, \mathrm{n})\right]=\mathrm{Tc}(\mathrm{q}) \times \mathrm{n}^{\mathrm{qh}(\mathrm{q})}=\mathrm{Tc}(\mathrm{q}) \times \mathrm{n}^{\tau(\mathrm{q})+1}$

where $\mathrm{c}(\mathrm{q})$ is the prefactor, $\mathrm{h}(\mathrm{q})$ is the generalized Hurst exponent, and $\tau(\mathrm{q})$ is the scaling function. The function $\mathrm{h}(\mathrm{q})$ determines whether $\tau(\mathrm{q})$ is linear or non-linear. In the case of unifractality, $\mathrm{h}(\mathrm{q})$ does not vary with $\mathrm{q}$, and $\tau(\mathrm{q})=\mathrm{qH}-1$ is linear in $\mathrm{q}$ with slope coefficient $\mathrm{H}$. The scaling behaviour of $\mathrm{S}_{\mathrm{q}}(\mathrm{T}, \mathrm{n})$ is the same for all $\mathrm{q}$, or $\mathrm{h}(\mathrm{q})=\mathrm{H}$ for all $\mathrm{q}$. In the case of multifractality, $h(q)$ varies with $q$, and there are different $h(q)$ for different moments. $\tau(q)=$ $\mathrm{qh}(\mathrm{q})-1$ is non-linear in $\mathrm{q}$. In this case, the scaling behaviour of $\mathrm{S}_{\mathrm{q}}(\mathrm{T}, \mathrm{n})$ varies with $\mathrm{q}$. In finance applications of multi-scaling behaviour, the degree of long-range dependence is permitted to differ for various powers of returns [21]. Let $\mathrm{q}^{*}$ denote the value of $\mathrm{q}$ such that $\mathrm{q}^{*} \mathrm{~h}\left(\mathrm{q}^{*}\right)=1$ and $\tau\left(\mathrm{q}^{*}\right)=0$. This definition implies

$\mathrm{H}=\mathrm{h}\left(\mathrm{q}^{*}\right) \quad$ or $\quad \mathrm{H}=1 / \mathrm{q}^{*}$

If the data generating process for returns is the MMAR with lognormal multipliers and $\lambda>1$, the scaling function $\tau(\mathrm{q})$ is quadratic in $\mathrm{q}[8],[22]$.

$\tau(q)=\tau_{0}+\tau_{1} q+\tau_{2} q^{2}$

For convenience and without any loss of generality, the intercept of (9) may be normalized, $\tau_{0}=-1$. Using (7) and (9), $\tau(q)$ can be estimated from the fixed-effects regression $\ln \left[\mathrm{S}_{\mathrm{q}}(\mathrm{T}, \mathrm{n})\right]=\mathrm{a}(\mathrm{q})+\left[-1+\tau_{1} \mathrm{q}+\tau_{2} \mathrm{q}^{2}\right] \ln (\mathrm{n})+$ error

where $a(q)=\ln [n T c(q)]$. 
In the previous literature, evidence of multifractality is commonly obtained from inspection of the multifractal spectrum, $f(\alpha)=\min _{q}[\alpha q-\tau(q)]$. Let $\alpha_{0}$ denote the value of $\alpha$ that maximizes $f(\alpha)$. Using $(8)$, it is easily shown

$\alpha_{0}=\tau_{1} \quad$ and $\quad \mathrm{H}=2 \tau_{2}\left[\left(\tau_{1}^{2}+4 \tau_{2}\right)^{1 / 2}-\tau_{1}\right]^{-1}$

Equation (11) provides an estimation method for $\mathrm{H}$. A test of $\mathrm{H}_{0}: \mathrm{H}=0.5$ against $\mathrm{H}_{1}: \mathrm{H} \neq 0.5$ is a test for NIID returns under $\mathrm{H}_{0}$, against either positive persistence and long memory $(\mathrm{H}>0.5)$, or negative persistence $(\mathrm{H}<0.5)$ under $\mathrm{H}_{1}$.

Figure 1 illustrates the interpretation of the multifractal spectrum. $f(\alpha)$ can be interpreted as the lower envelope of the set of linear functions $\alpha q-\tau(q)$. In addition to $\alpha_{0}$, other reference points in Figure 1 are $\left(\alpha_{1}, \alpha_{1} / H\right),\left(\alpha_{\text {MIN }}, 0\right)$, and $\left(\alpha_{\text {MAX }}, 0\right)$. Since $\tau\left(q^{*}\right)=0$ and $q^{*}=1 / H$, the linear function $\alpha q^{*}-\tau\left(q^{*}\right)$ intersects the origin, and is tangential to $f(\alpha)$ at the point $\left(\alpha_{1}, \alpha_{1} / H\right)$. $\alpha_{\text {MIN }}$ and $\alpha_{\text {MAX }}$ are the minimum and maximum values of $\alpha$ for which $f(\alpha) \geq 0$.

In the case of unifractality, the scaling function is $\tau(q)=-1+H q$, and all of the lines of tangency pass through the same point, $(\mathrm{H}, 1)$. The lower envelope is degenerate, and the multifractal spectrum has the appearance of a spike, located at $\alpha_{0}=\alpha_{1}=\alpha_{\mathrm{MIN}}=\alpha_{\mathrm{MAX}}=H$, such that $f(\alpha)=1$ for $\alpha=H$, and $f(\alpha)=-\infty$ for $\alpha \neq H[20]$.

The parameter $\lambda$ is estimated using the relationship

$\alpha_{0}=\lambda \mathrm{H} \quad$ or $\quad \lambda=\alpha_{0} / \mathrm{H}$

In the case of unifractality, $\alpha_{0}=\mathrm{H}$ implies $\lambda=1$. Accordingly, test of $\mathrm{H}_{0}: \lambda=1$ against $\mathrm{H}_{1}: \lambda>1$ is a test for the null hypothesis of unifractality against an alternative hypothesis of multifractality. 


\section{Hypothesis tests for the presence of long memory and multifractality}

The hypothesis tests reported in this study are derived from the synthetic distributions of the estimators of $\mathrm{H}$ and $\lambda$ based on (11) and (12), obtained from 5,000 replications of NIID series and denoted $\{\overline{\mathrm{H}}, \bar{\lambda}\}$. We examine tests of the following hypotheses: (i) $\mathrm{H}_{0}: \mathrm{H}=0.5$ against $\mathrm{H}_{1}: \mathrm{H} \neq 0.5$; (ii) $\mathrm{H}_{0}: \lambda=1$ against $\mathrm{H}_{1}: \lambda>1$; and (iii) $\mathrm{H}_{0}:\{\lambda=1, \mathrm{H}=0.5\}$. Using $\{\overline{\mathrm{H}}, \bar{\lambda}\}$ obtained from the Monte Carlo simulation and the estimated $\mathrm{H}$ and $\lambda$ for an observed series, denoted $\{\hat{\mathrm{H}}, \hat{\lambda}\}$, the p-value for (i) is $2 \min \left\{\pi_{\mathrm{H}}, 1-\pi_{\mathrm{H}}\right\}$ where $\pi_{\mathrm{H}}=5000^{-1} \sum 1_{\overline{\mathrm{H}}>\hat{\mathrm{H}}}, 1_{\overline{\mathrm{H}}>\hat{\mathrm{H}}}$ is the indicator function for $\overline{\mathrm{H}}>\hat{\mathrm{H}}$, and the summation is over the 5,000 simulated $\overline{\mathrm{H}}$. The pvalue for (ii) is $\pi_{\lambda}=5000^{-1} \sum 1_{\bar{\lambda}>\hat{\lambda}}$, where $1_{\bar{\lambda}>\hat{\lambda}}$ is the indicator function for $\bar{\lambda}>\hat{\lambda}$ and the summation is the same. The p-value for (iii), denoted $\pi_{\mathrm{H}, \lambda}$, is obtained iteratively as follows:

1. On the first iteration $(j=1)$, set the initial $p$-value to $p=1-0.001 j$.

2. Using the simulated $\{\overline{\mathrm{H}}, \bar{\lambda}\}$, fit the confidence ellipse

$$
\gamma_{1} \lambda^{2}+\gamma_{2} \mathrm{H}^{2}+\gamma_{3} \lambda \mathrm{H}+\gamma_{4} \lambda+\gamma_{5} \mathrm{H}=\gamma_{0}(\mathrm{p})
$$

3. For a significance level of $\alpha=\mathrm{p}, \mathrm{H}_{0}$ is rejected under any of the following conditions:

$$
\begin{aligned}
& \hat{\mathrm{H}}<\mathrm{H}_{\mathrm{MIN}} ; \quad \hat{\mathrm{H}}>\mathrm{H}_{\mathrm{MAX}} ; \quad\left\{\lambda_{1} \leq \hat{\lambda} \leq \lambda_{\mathrm{MAX}} \quad \text { and } \hat{\mathrm{H}}<\mathrm{f}_{1}(\hat{\lambda})\right\} ; \\
& \left\{\lambda_{2} \leq \hat{\lambda} \leq \lambda_{\mathrm{MAX}} \text { and } \hat{\mathrm{H}}>\mathrm{f}_{2}(\hat{\lambda})\right\}
\end{aligned}
$$

where $f_{1}(\lambda)=2^{-1}\left\{-\left(\gamma_{3} \lambda+\gamma_{4}\right)-\left[\left(\gamma_{3} \lambda+\gamma_{5}\right)^{2}-4 \gamma_{2}\left(\lambda^{2}+\gamma_{4} \lambda-\gamma_{0}(p)\right)\right]^{1 / 2}\right\}$

$$
\begin{aligned}
& \mathrm{f}_{2}(\lambda)=2^{-1}\left\{-\left(\gamma_{3} \lambda+\gamma_{4}\right)+\left[\left(\gamma_{3} \lambda+\gamma_{5}\right)^{2}-4 \gamma_{2}\left(\lambda^{2}+\gamma_{4} \lambda-\gamma_{0}(\mathrm{p})\right)\right]^{1 / 2}\right\} \\
& \lambda_{1}=\underset{\lambda}{\arg \min } \mathrm{f}_{1}(\lambda) ; \mathrm{H}_{\mathrm{MIN}}=\mathrm{f}_{1}\left(\lambda_{1}\right) ; \lambda_{2}=\underset{\lambda}{\arg \max } \mathrm{f}_{2}(\lambda) ; \mathrm{H}_{\mathrm{MAX}}=\mathrm{f}_{2}\left(\lambda_{2}\right) \\
& \mathrm{g}(\mathrm{H})=2^{-1}\left\{-\left(\gamma_{3} \mathrm{H}+\gamma_{4}\right)+\left[\left(\gamma_{3} \mathrm{H}+\gamma_{4}\right)^{2}-4\left(\gamma_{2} \mathrm{H}^{2}+\gamma_{5} \mathrm{H}-\gamma_{0}(\mathrm{p})\right)\right]^{1 / 2}\right\} \\
& \mathrm{H}_{2}=\underset{\mathrm{H}}{\arg \max } \mathrm{g}(\mathrm{H}) ; \lambda_{\mathrm{MAX}}=\mathrm{g}\left(\mathrm{H}_{2}\right)
\end{aligned}
$$


4. If $\mathrm{H}_{0}$ is rejected at step 3 , proceed to the second iteration by resetting $\mathrm{j}=2$ and $\mathrm{p}=1-$ $0.001 \mathrm{j}$, and repeat steps 2,3 . The procedure is repeated for further iterations $(j=3, \ldots, 999)$, and terminates when a value for $\mathrm{p}$ is obtained at which $\mathrm{H}_{0}$ is not rejected.

Figure 2 illustrates the construction of the rejection region in test (iii). Table 1 reports the size and power functions for tests (i), (ii) and (iii) for all permutations of $H$ and $\lambda$ drawn from the following sets of values: $\mathrm{H}=\{0.5,0.54,0.58,0.62\}, \lambda=\{1,1.04,1.08,1.12\}$. The power functions are computed by applying the estimators of $H$ and $\lambda$ based on (11) and (12) to simulated series generated in accordance with (1) to (4), with NIID random numbers used to generate $\mathrm{m}\left[\eta_{\mathrm{t}}(\mathrm{k})\right]$ and $\mathrm{u}_{\mathrm{t}}$.

Test (i) is oversized if $\lambda>1$ (multifractality): the test rejects the null hypothesis of no positive or negative persistence too frequently. For $\mathrm{H}>0.5$, the power of test (i) increases monotonically with $\mathrm{H}$. Test (ii) is undersized if $\mathrm{H}>0.5$ (positive persistence and long memory): the test fails to reject the null hypothesis of no multifractality too frequently. For $\lambda>1$, the power increases monotonically with $\lambda$. Small departures from $\lambda=1$ (e.g. $\lambda=1.04$ ) are more easily detected by (ii) than are small departures from $\mathrm{H}=0.5$ (e.g. $\mathrm{H}=0.54$ ) by (i). Test (iii), however, is effective in detecting departures from $\{\mathrm{H}, \lambda\}=\{0.5,1\}$. The power functions increase monotonically with both $\mathrm{H}$ and $\lambda$. Consistent with (i) and (ii), small departures from $\lambda=1$ are more easily detected than small departures from $\mathrm{H}=0.5$.

\section{Empirical illustration: Fitting the MMAR to foreign exchange rate returns}

Table 2 and Figure 2 report results for the estimation and hypothesis test procedures described in Sections 3 and 4, applied to $\mathrm{T}=5,000$ daily logarithmic returns for 12 national currency exchange rates against the US dollar, for the period January 1993 to February 2012. The data were sourced from Datastream. 
The left-hand panel of Table 2 compares the realized estimates of $\mathrm{H}$ and $\lambda$ based on the log returns series pre-filtered to eliminate short-range dependence by fitting an autoregressive model to the observed returns, with critical values from NIID Monte Carlo simulations. Pre-filtering, however, can produce distortions in the test for long-range dependence. Accordingly, the right-hand panel of Table 2 compares realized estimates based on the unfiltered log returns series with critical values from recursive Monte Carlo simulations. For the latter, we construct 5,000 simulated series using $r_{i, t}^{*}=\sum_{\tau=1}^{k} \hat{\rho}_{\tau} r_{i, t-\tau}^{*}$ where $\mathrm{u}_{\mathrm{i}, \mathrm{t}}$ are NIID and $\hat{\rho}_{\tau}$ are the coefficients from the $\mathrm{k}$ 'th order autoregressive model fitted to the observed returns, where $\mathrm{k}$ is the maximum lag-length that yields a significant coefficient. Only those values of $\tau$ in the range $1 \leq \tau \leq \mathrm{k}$ for which $\hat{\rho}_{\tau}$ is significant at the 0.05 level are included in the construction of $r_{i, t}^{*}$. The highest value of $k$ obtained for any currency, i.e. the highest-order autoregressive model required to represent short-range dependence, is $\mathrm{k}=12 .^{2}$

According to Table 2, test (i) fails to reject $\mathrm{H}_{0}: \mathrm{H}=0.5$ in favour of $\mathrm{H}_{1}: \mathrm{H} \neq 0.5$ at the 0.05 level for any of the 12 exchange rate log returns series, using either the filtered or the unfiltered returns. By contrast, test (ii) rejects $\mathrm{H}_{0}: \lambda=1$ in favour of $\mathrm{H}_{1}: \lambda>1$ for 11 of the 12 series, the sole exception being the GB pound. Consistent with the results of (i) and (ii), test (iii) rejects $\mathrm{H}_{0}:\{\lambda=1, \mathrm{H}=0.5\}$ at the 0.05 level for 11 of the 12 series, the sole exception being the GB pound as before. ${ }^{3,4}$ The contrast between the results for the GB pound, traded in large

\footnotetext{
${ }^{2}$ Separate AR(k) models are fitted to the observed returns series for each currency, with the value of $\mathrm{k}$ determined by estimating an $\mathrm{AR}(\mathrm{k})$ specification with $\mathrm{k}=18$, and then re-estimating with $\mathrm{k}$ reduced iteratively in steps of one, if the estimated coefficient on $r_{i, t-k}{ }^{*}$ in the previous iteration was insignificant. The search terminates when a specification is identified that yields a significant estimated coefficient on $r_{i, t-k}^{*}$.

${ }^{3}$ During the 2007-09 financial crisis, the GB pound fell sharply in value against the US dollar. To investigate whether this may have influenced the estimation of $\mathrm{H}$ and $\lambda$ for the $\mathrm{UK}$, we repeat the estimations for the subperiod 16/05/1997-01/01/2007. The estimated $\lambda$ is insignificant for both sub-periods, and the result for the GB pound reported in Table 2 does not appear to be related to the financial crisis.

${ }^{4}$ The estimation procedure described in Section 3 is based upon an assumption that $\mathrm{u}_{\mathrm{t}}$ are normally distributed. As an informal check on the validity of this assumption, for each of the 12 series we compare the sample
} 
volume in a highly liquid market, ${ }^{5}$ and those for the other 11 currencies, suggest an association between multifractality and market inefficiency [6]. The high estimated $\lambda$ for the Japanese yen, also traded in large volumes but in a market subject to regular intervention by the Bank of Japan [23], might reflect a tendency for central bank intervention to induce jumps in exchange rate volatility [24].

The empirical tests provide no support for the hypothesis that exchange rate returns are characterized by either long memory and positive persistence, or negative persistence. With the exception of the GB pound, however, the tests reject the null hypothesis of NIID returns in favour of an alternative hypothesis of multifractality, of a form consistent with a data generating process of the form $\Delta^{(1)} \mathrm{p}_{\mathrm{t}}=\mathrm{u}_{\mathrm{t}}$, with $\mathrm{u}_{\mathrm{t}} \sim \mathrm{N}(0, \Delta \theta(\mathrm{t}))$ and $\theta(\mathrm{t})$ defined as in $(2)$. Among the nested model specifications that are investigated in this study, it appears that exchange rate returns are most appropriately characterized by a variant of the MMAR that applies a multifractal time-deformation process to NIID returns.

\section{Conclusion}

In this paper, we develop statistical testing criteria, based on conventional hypothesis testing methodology, to facilitate comparisons between processes that are characterized by specifications nested within the MMAR, and processes for which the more parsimonious specifications are rejected in favour of the MMAR. Monte Carlo simulations are used to generate critical values for the relevant tests. The methods are illustrated by means of an

kurtosis coefficient with the upper limit of a $95 \%$ one-sided confidence interval for the sample kurtosis, obtained by running 5,000 simulations of $\Delta^{(1)} \mathrm{p}_{\mathrm{t}}=\mathrm{u}_{\mathrm{t}}$ where $\mathrm{u}_{\mathrm{t}} \sim \mathrm{N}(0, \Delta \theta(\mathrm{t}))$ and $\Delta \theta(\mathrm{t})$ is defined in accordance with (2) for $\ln \mathrm{m}\left[\eta_{\mathrm{t}}(\mathrm{k})\right] \sim \mathrm{N}(\lambda, 2(\lambda-1) / \ln 2)$. The parameter $\lambda$ used in the simulations is the estimated $\lambda$ for each series, with the sole exception of the UK for which the simulation is based on $\lambda=1$. For all 11 series for which the estimated $\lambda$ in Table 2 is significantly greater than one the sample kurtosis lies within the confidence interval, suggesting that the normality assumption in respect of $\mathrm{u}_{\mathrm{t}}$ is reasonable. For the UK, the sample kurtosis of 6.38 lies outside the confidence interval, which suggests that the normality assumption is not appropriate. IID returns drawn from a student-t distribution with approximately six degrees of freedom would replicate the sample kurtosis in the observed UK series.

${ }^{5}$ Our results for GBP are in contrast to those of [19], which reports stronger evidence of multifractality for USD/GBP than for any of the other currency pairs investigated: a finding the authors acknowledge is contrary to prior expectation. 
empirical analysis of the daily log returns for the exchange rates of 12 currencies against the US dollar for the period 1993-2012. Among the nested model specifications that are investigated in this study, 11 of the 12 exchange rate returns series are most appropriately characterized by a variant of the MMAR that applies a multifractal time-deformation process to NIID returns. In the case of the GB pound/US dollar daily exchange rate series only, a currency pair traded in large volume in a liquid market, the tests fail to reject the null hypothesis that returns are NIID.

\section{References}

[1] Wei, H. L, Billings, S. A. 2009. Power-law behaviour evaluation from foreign exchange market data using a wavelet transform method. Physics Letters A 373, 3324-3329.

[2] Goddard, J., Onali, E. 2012. Short and long memory in stock returns data. Economics Letters 117, 253-255.

[3] Tan, P. P., Galagedera, D. U. A., Maharaj, E. A., 2012. A wavelet based investigation of long memory in stock returns. Physica A 391, 2330-2341.

[4] Yang, C.-X., Wang, R., Hu, S. 2013. Modeling and analysis of an agent-based model for Chinese stock market. Physics Letters A 377, 2041-2046.

[5] Onali, E., Goddard, J. 2009. Unifractality and multifractality in the Italian stock market. International Review of Financial Analysis 18, 154-163.

[6] Zunino, L., Tabak, B.M., Figliola, A., Perez, D.G., Garavaglia, M., Rosso, O.A. 2008. A multifractal approach for stock market inefficiency. Physica A 387, 6558-6566.

[7] Cajueiro, D.O., Tabak, B.M. 2009. Multifractality and herding behaviour in the Japanese stock market. Chaos, Solitons and Fractals 40, 497-504. 
[8] Calvet, L., Fisher, A. 2002. Multifractality in asset returns: theory and evidence. The Review of Economics and Statistics 84, 381-406.

[9] Calvet, L., Fisher, A. 2001. Forecasting multifractal volatility. Journal of Econometrics $105,27-58$.

[10] Barunik, J., Aste, T., Di Matteo, T., Liu, R. 2012. Understanding the source of multifractality in financial markets. Physica A 391, 4234-4251.

[11] Kantelhardt, J.W., Zschiegner, S.A., Koscielny-Bunde, E., Havlin, S., Bunde, A., Stanley, H.E. 2002. Multifractal detrended fluctuation analysis of nonstationary time series. Physica A 316, 87-114.

[12] Rizvi, S.A.R., Dewandaru, G., Bacha, O.I., Masih, A.M.M. 2014. An analysis of stock market efficiency: Developed vs Islamic stock markets using MF-DFA. Physica A 407, 86-99.

[13] Arshad, S., Rizvi, S.A.R. 2015. The troika of business cycle, efficiency and volatility. An East Asian perspective. Physica A 419, 158-170.

[14] Dewandaru, G., Masih, R., Bacha, O.I., Masih, A.M.M. 2015. The contribution of fractal finance to momentum trading strategies: The case of Islamic equities using multi-fractal de-trended fluctuation analysis (MF-DFA). Physica A, forthcoming.

[15] Di Matteo, T., Aste, T., Dacorogna, M.M. 2005. Long-term memories of developed and emerging markets: using the scaling analysis to characterize their stage of development. Journal of Banking and Finance 29, 827-851.

[16] Kim, K., Yoon, S.-M. 2004. Multifractal features of financial markets. Physica A 344, $272-278$.

[17] Norouzzadeh, P., Rahmani, B. 2006. A multifractal detrended fluctuation description of Iranian rial-US dollar exchange rate, Physica A 367, 328-336.

[18] Oh, G., Kim, S., Eom, C. 2008. Long-term memory and volatility clustering in high- 
frequency price changes. Physica A 387, 1247-1254.

[19] Wang, Y., Wu, C., Pan, Z. 2011. Multifractal Detrended Moving Average Analysis on the US Dollar Exchange Rates. Physica A 390, 3512-3523.

[20] Fisher, A., Calvet, L., Mandelbrot, B. 1997. Multifractality of Deutschemark / US Dollar Exchange Rates. Cowles Foundation Discussion Paper No. 1166.

[21] Lux, T. 2007. The Markov-switching multifractal model of asset returns: GMM estimation and linear forecasting of volatility. Journal of Business and Economic Statistics 26, 194-210.

[22] Calvet, L., Fisher, A., Mandelbrot, B. Large Deviations and the Distribution of Price Changes. Cowles Foundation Discussion Paper No. 1165.

[23] Kearns, J., Rigobon, R. 2002. Identifying the efficacy of central bank interventions: the Australian case. NBER working paper 9062.

[24] Beine, M., Laurent, S. 2003. Central bank interventions and jumps in double long memory models of daily exchange rates. Journal of Empirical Finance 10, 641-660. 
Table $1 \quad$ Size and power functions

\begin{tabular}{|c|c|c|c|c|c|c|c|c|c|c|c|c|c|}
\hline & \multicolumn{5}{|c|}{ Significance level $=0.10$} & \multicolumn{4}{|c|}{ Significance level $=0.05$} & \multicolumn{4}{|c|}{ Significance level $=0.01$} \\
\hline \multicolumn{2}{|c|}{$\mathrm{H} \rightarrow$} & 0.5 & 0.54 & 0.58 & 0.62 & 0.5 & 0.54 & 0.58 & 0.62 & 0.5 & 0.54 & 0.58 & 0.62 \\
\hline \multicolumn{14}{|c|}{ (i) Test $\mathrm{H}_{0}: \mathrm{H}=0.5$ against $\mathrm{H}_{1}: \mathrm{H} \neq 0.5$} \\
\hline 1.00 & $\mathrm{~T}=2500$ & .100 & .255 & .583 & .836 & .050 & .173 & .473 & .773 & .010 & .067 & .282 & .617 \\
\hline 1.04 & & .167 & .273 & .540 & .789 & .104 & .194 & .443 & .726 & .036 & .089 & .276 & .567 \\
\hline 1.08 & & .225 & .292 & .509 & .738 & .154 & .215 & .423 & .676 & .071 & .106 & .270 & .522 \\
\hline 1.12 & & .267 & .309 & .489 & 693 & .194 & .235 & .407 & .629 & .096 & .124 & .259 & .483 \\
\hline 1.00 & $\mathrm{~T}=5000$ & .100 & .317 & .700 & .930 & .050 & .228 & .615 & .893 & .010 & .088 & .395 & .758 \\
\hline 1.04 & & .160 & .317 & .646 & .893 & .101 & .237 & .566 & .843 & .031 & .103 & .364 & .704 \\
\hline 1.08 & & .223 & .327 & .600 & .841 & .154 & .247 & .519 & .787 & .064 & .118 & .337 & .647 \\
\hline 1.12 & & .274 & .340 & .556 & .791 & .203 & .263 & .475 & .735 & .097 & .131 & .315 & .594 \\
\hline \multicolumn{14}{|c|}{ (ii) Test $\mathrm{H}_{0}: \lambda=1$ against $\mathrm{H}_{1}: \lambda>1$} \\
\hline 1.00 & $\mathrm{~T}=2500$ & .100 & .054 & .027 & .011 & .050 & .024 & .009 & .003 & .010 & .004 & .001 & .000 \\
\hline 1.04 & & .688 & .614 & .527 & .437 & .606 & .515 & .418 & .316 & .443 & .337 & .237 & .152 \\
\hline 1.08 & & .862 & .823 & .773 & .717 & .820 & .767 & .705 & .621 & .715 & .633 & .531 & .426 \\
\hline 1.12 & & .914 & .901 & .879 & .848 & .893 & .868 & .835 & .788 & .823 & .777 & .716 & .628 \\
\hline 1.00 & $\mathrm{~T}=5000$ & .100 & .049 & .024 & .005 & .050 & .021 & .005 & .001 & .010 & .001 & .000 & .000 \\
\hline 1.04 & & .791 & .727 & .645 & .558 & .733 & .651 & .556 & .455 & .605 & .495 & .381 & .268 \\
\hline 1.08 & & .931 & .912 & .881 & .839 & .912 & .881 & .842 & .789 & .861 & .802 & .731 & .640 \\
\hline 1.12 & & .969 & .960 & .950 & .930 & .960 & .950 & .929 & .903 & .934 & .909 & .874 & .829 \\
\hline \multicolumn{14}{|c|}{ (iii) Test $\mathrm{H}_{0}:\{\mathrm{H}=0.5, \lambda=1\}$} \\
\hline 1.00 & $\mathrm{~T}=2500$ & .100 & .186 & .461 & .759 & .050 & .099 & .326 & .649 & .010 & .018 & .110 & .362 \\
\hline 1.04 & & .581 & .625 & .748 & .883 & .478 & .493 & .620 & .802 & .292 & .241 & .327 & .532 \\
\hline 1.08 & & .826 & .849 & .903 & .954 & .762 & .774 & .831 & .912 & .587 & .567 & .609 & .732 \\
\hline 1.12 & & .919 & .934 & .960 & .980 & .882 & .892 & .925 & .961 & .770 & .756 & .788 & .855 \\
\hline 1.00 & $\mathrm{~T}=5000$ & .100 & .235 & .595 & .877 & .050 & .145 & .472 & .809 & .010 & .034 & .232 & .603 \\
\hline 1.04 & & .702 & .759 & .884 & .968 & .617 & .655 & .803 & .931 & .435 & .413 & .564 & .792 \\
\hline 1.08 & & .919 & .942 & .973 & .992 & .883 & .906 & .948 & .984 & .778 & .783 & .850 & .932 \\
\hline 1.12 & & .973 & .978 & .993 & .997 & .959 & .966 & .982 & .996 & .912 & .918 & .947 & .976 \\
\hline
\end{tabular}


Table $2 \quad$ Empirical results

\begin{tabular}{|l|ccccc|ccccc|}
\hline & \multicolumn{3}{|c}{ Filtered returns, critical values from NIID simulations } & \multicolumn{3}{c|}{ Unfiltered returns, critical values from AR simulations } \\
& $\hat{\mathrm{H}}$ & $\hat{\lambda}$ & $\pi_{\mathrm{H}}$ & $\pi_{\lambda}$ & $\pi_{\mathrm{H}, \lambda}$ & $\hat{\mathrm{H}}$ & $\hat{\lambda}$ & $\pi_{\mathrm{H}}$ & $\pi_{\lambda}$ & $\pi_{\mathrm{H}, \lambda}$ \\
\hline Australia & 0.527 & 1.121 & 0.417 & 0.000 & 0.000 & 0.523 & 1.121 & 0.394 & 0.000 & 0.000 \\
Canada & 0.518 & 1.109 & 0.577 & 0.000 & 0.000 & 0.493 & 1.116 & 0.560 & 0.000 & 0.000 \\
Denmark & 0.510 & 1.076 & 0.730 & 0.000 & 0.004 & 0.509 & 1.076 & 0.742 & 0.003 & 0.010 \\
Israel & 0.496 & 1.130 & 0.980 & 0.000 & 0.000 & 0.515 & 1.122 & 0.840 & 0.000 & 0.000 \\
Japan & 0.495 & 1.182 & 0.968 & 0.000 & 0.000 & 0.509 & 1.175 & 0.851 & 0.000 & 0.000 \\
Norway & 0.495 & 1.071 & 0.974 & 0.001 & 0.013 & 0.486 & 1.073 & 0.970 & 0.004 & 0.025 \\
New Zealand & 0.555 & 1.062 & 0.109 & 0.005 & 0.005 & 0.549 & 1.075 & 0.092 & 0.003 & 0.003 \\
Singapore & 0.514 & 1.116 & 0.644 & 0.000 & 0.000 & 0.534 & 1.130 & 0.469 & 0.000 & 0.000 \\
Sweden & 0.502 & 1.064 & 0.878 & 0.003 & 0.029 & 0.503 & 1.065 & 0.905 & 0.007 & 0.036 \\
Switzerland & 0.478 & 1.115 & 0.613 & 0.000 & 0.000 & 0.487 & 1.117 & 0.810 & 0.000 & 0.000 \\
Taiwan & 0.527 & 1.141 & 0.418 & 0.000 & 0.000 & 0.560 & 1.113 & 0.303 & 0.000 & 0.000 \\
UK & 0.510 & 0.980 & 0.720 & 0.955 & 0.830 & 0.491 & 0.978 & 0.708 & 0.967 & 0.811 \\
\hline
\end{tabular}


Graphs for Figure 1: Multifractal spectrum.

(a)

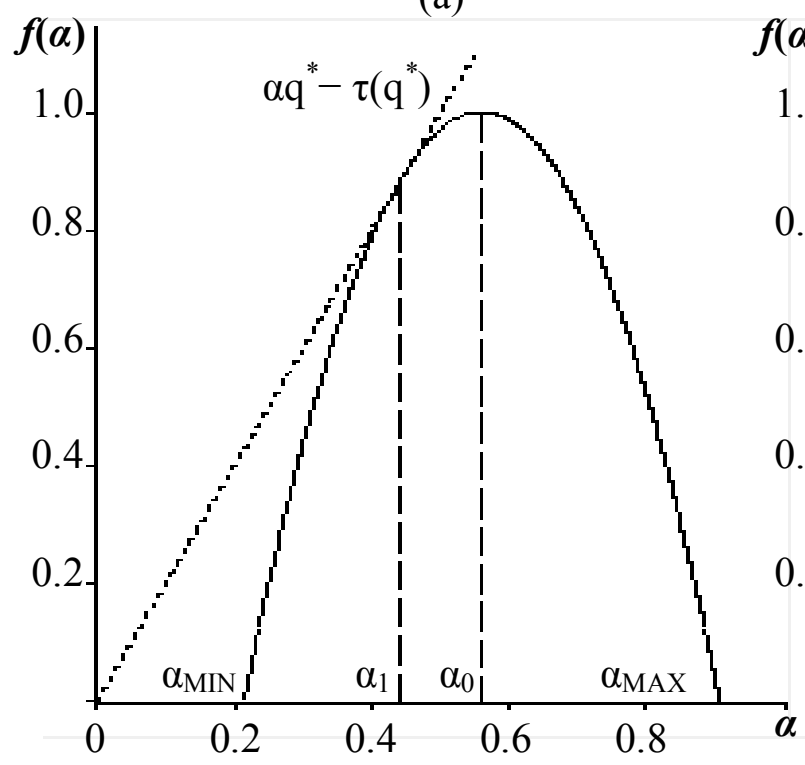

(b)

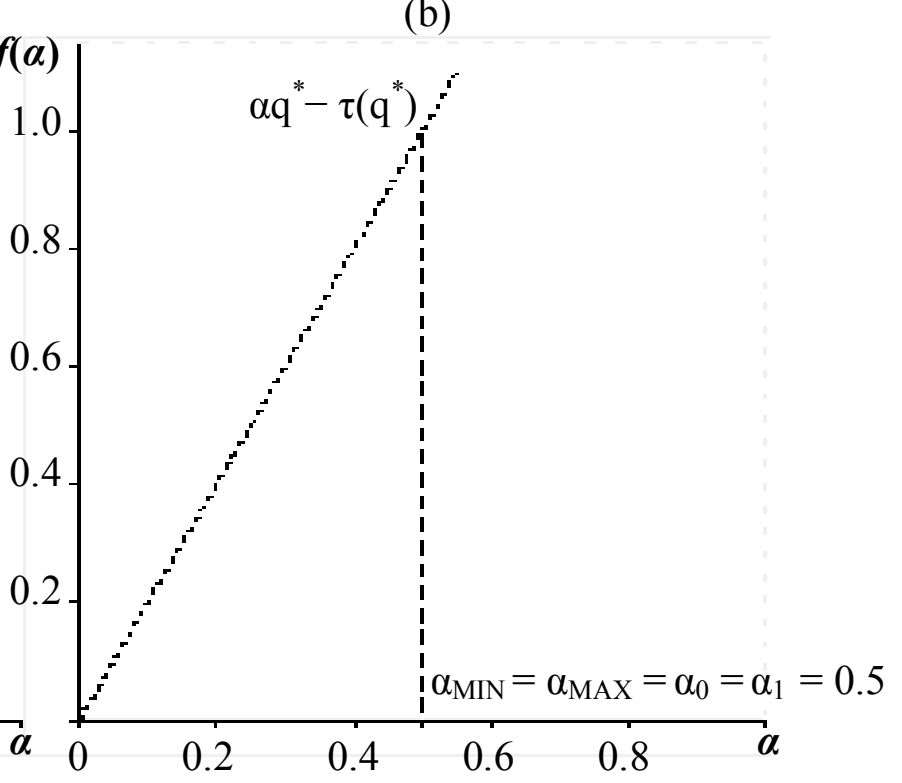

Note

Panel (a) illustrates the multifractal spectrum $\mathrm{f}(\alpha)$ for $\mathrm{H}=0.5, \lambda=1.12$. These values imply $\alpha_{0}=0.56, \alpha_{1}=0.44, \alpha_{\mathrm{MIN}}=0.214, \alpha_{\mathrm{MAX}}=0.906$. Panel (b) illustrates the multifractal spectrum $\mathrm{f}(\alpha)$ for $\mathrm{H}=0.5, \lambda=1$ (the multifractal spectrum degenerates to a point). These values imply $\alpha_{0}=\alpha_{1}=\alpha_{\mathrm{MIN}}=\alpha_{\mathrm{MAX}}=0.5$. 
Graph for Figure 2: 95\% confidence 'ellipse' (one-sided test for $\lambda$; two-sided test for $\mathrm{H}$ ). Filtered returns, critical values from NIID simulations

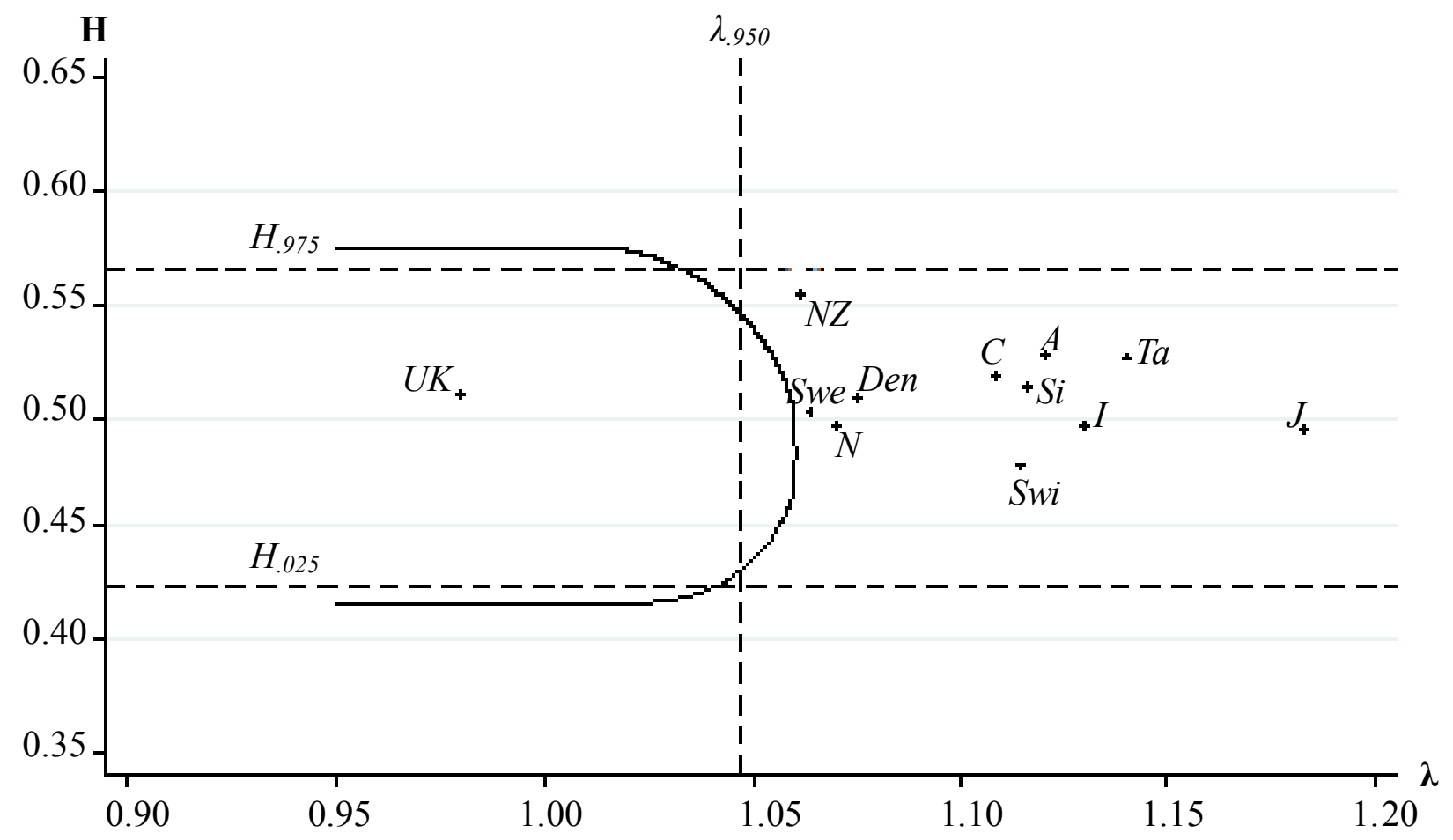

$\underline{\text { Note }}$

$\mathrm{A}=$ Australian Dollar; $\mathrm{C}=$ Canadian Dollar; $\mathrm{D}=$ Danish Krone; $\mathrm{I}=$ Israeli New Sheqel; $\mathrm{J}=$ Japanese Yen; $\mathrm{N}=$ Norwegian Krone; $\mathrm{NZ}=$ New Zealand Dollar; $\mathrm{Si}=$ Singapore Dollar; Swe $=$ Swedish Krona; Swi $=$ Swiss Franc; $\mathrm{Ta}=$ Taiwanese Dollar; UK $=$ British Pound.

$\lambda .950=5 \%$ upper critical value for $\lambda$ (one-sided test).

$H_{.975}=5 \%$ upper critical value for $\mathrm{H}$ (two-sided test).

$H_{.025}=5 \%$ lower critical value for $\mathrm{H}$ (two-sided test). 